\title{
Baseline cardiac output and its alterations during ibuprofen treatment for patent ductus arteriosus in preterm infants
}

\author{
Kai-Hsiang Hsu ${ }^{1,2^{*}}$ (D), Tai-Wei Wu ${ }^{3}$ I-Hsyuan Wu', Mei-Yin Lai ${ }^{1,2}$, Shih-Yun Hsu ${ }^{1,4}$, Hsiao-Wen Huang ${ }^{1}$, Tze-Yee Mok', \\ Cheng-Chung Lee ${ }^{1,2}$ and Reyin Lien ${ }^{1}$
}

\begin{abstract}
Background: Infants with hemodynamically significant patent ductus arteriosus (PDA) may physiologically compensate with a supranormal cardiac output (CO). As such, a supranormal CO may be a surrogate marker for a significant PDA or indicate a failed response to PDA closure by ibuprofen. Electrical cardiometry (EC) is an impedance-based monitor that can continuously and non-invasively assess $\mathrm{CO}\left(\mathrm{CO}_{\mathrm{EC}}\right)$. We aimed to trend $\mathrm{CO}_{\mathrm{EC}}$ through ibuprofen treatment for PDA in preterm infants.

Methods: We reviewed our database of preterm infants receiving ibuprofen for PDA closure. Response to ibuprofen was defined as no ductal flow in echocardiography $\leq 24 \mathrm{~h}$ after treatment. Responders were compared with gestational age (GA) and postnatal age matched non-responders and their trends of $C O_{E C}$ were compared. Both groups' baseline $\mathrm{CO}_{\mathrm{EC}}$ were further compared to the reference infants without PDA.

Results: Eighteen infants (9 responders and 9 non-responders) with median (interquatile range) GA 27.5 (26.6-28.6) weeks, birthweight 1038 (854-1218) g and age 3.5 (3.0-4.0) days were studied. There were positive correlations between $\mathrm{CO}_{\mathrm{EC}}$ and ductal diameter and left atrium/ aortic root ratio $(r=0.521$ and $0.374, p<0.001$, respectively). Both responders and non-responders had significantly higher baseline $\mathrm{CO}_{\mathrm{EC}}$ than the reference. Although there was no significant within-subject alteration of $\mathrm{CO}_{\mathrm{EC}}$ during ibuprofen treatment, there was a between-subject difference indicating non-responders had generally higher $\mathrm{CO}_{\mathrm{EC}}$.

Conclusions: The changes of $\mathrm{CO}_{\mathrm{EC}}$ during pharmacological closure of PDA is less drastic compared to surgical closure. Infants with PDA had higher baseline $\mathrm{CO}_{\mathrm{EC}}$ compared to those without PDA, and non-responders had higher $\mathrm{CO}_{\mathrm{EC}}$ especially at baseline compared to responders.
\end{abstract}

Keywords: Cardiac output, Electrical cardiometry, Hemodynamic, Non-invasive monitor, Patent ductus arteriosus, Preterm infant

\section{Introduction}

Patent ductus arteriosus (PDA) is common among preterm infants and failure of ductal closure is associated with complications and poor outcomes [1]. Non-selective cyclooxygenase (COX) inhibitor, such as ibuprofen, is the pharmacological choice of treatment for PDA based on its

\footnotetext{
* Correspondence: khsu@cgmh.org.tw

'Division of Neonatology, Department of Pediatrics, Chang Gung Memorial Hospital Linkou Branch, Taoyuan, Taiwan

${ }^{2}$ Graduate Institute of Clinical Medical Science, Chang Gung University, Taoyuan, Taiwan

Full list of author information is available at the end of the article
}

action of prostaglandin inhibition that promotes ductal constriction. Both the intravenous and oral routes of ibuprofen administration appear comparably effective for ductal closure [2]. However, successful PDA closure by pharmacological treatment is not always definite or predictable [3]. The rate of ductal closure after COX inhibitors varies from 60 to $85 \%$ in preterm infants and is even less effective in extremely premature infants [4-6].

Echocardiography is often used to evaluate hemodynamic significance of PDA [7]. In general, pharmacological closure of PDA is less successful in infants with ductal diameter $>2$ $\mathrm{mm}[8]$. Lower ductal maximum velocity, which is usually 
associated with a larger PDA or higher pulmonary pressure, is another predictor of treatment failure $[4,8]$. Furthermore, an increase in left ventricular cardiac output (CO) has been positively correlated with significant ductal shunting $[7,9,10]$ and PDA severity [11]. The underlying reason is that a PDA with significant left-to-right flow may lead to a compensatory increase in $\mathrm{CO}$ in order to maintain systemic blood flow [12, 13]. Indeed, following closure of ductus after COX inhibitor therapy [12] or surgical ligation [10, 14], CO normalizes accordingly. We therefore hypothesized that a supranormal $\mathrm{CO}$ in the first week of life in extreme premature infants may indicate a hemodynamically significant PDA and that we could observe $\mathrm{CO}$ changes during pharmacological treatment. However, the ability to perform neonatal functional echocardiography requires practice, training and mentorship [15]. Furthermore, the use of echocardiography to gather meaningful hemodynamic data often necessitates serial assessments that can be tedious and labor-intensive.

Electrical cardiometry (EC) is a non-invasive, impedancebased monitor that provides absolute $\mathrm{CO}$ estimates in clinical practice [16]. Unlike echocardiography, EC is simple to apply, continuous in measurements and not operatordependent. Comparisons between $\mathrm{CO}$ measured by EC $\left(\mathrm{CO}_{\mathrm{EC}}\right)$ and echocardiography have been studied in term [17] and preterm [18-20] infants with and without PDA. Although $\mathrm{CO}$ values measured by EC and echocardiography may not be interchangeable, it has been suggested that EC can be useful in trending $\mathrm{CO}$ changes in the clinical setting [20]. Hemodynamic reference by EC for neonates without PDA and without invasive ventilation support has been established, and $\mathrm{CO}_{\mathrm{EC}}$ is positively correlated with gestational age (GA) and weight [21]. In addition, EC was used to monitor the effects of ductal ligation on $\mathrm{CO}_{\mathrm{EC}}$, which revealed an initial decline in $\mathrm{CO}_{\mathrm{EC}}$ followed by recovery [22]. Utilizing the ability of $\mathrm{EC}$ to continuously measure $\mathrm{CO}_{\mathrm{EC}}$, we aimed to identify significant changes in $\mathrm{CO}_{\mathrm{EC}}$ during attempted pharmacological closure and compared $\mathrm{CO}_{\mathrm{EC}}$ characteristics in responders versus non-responders.

\section{Methods}

\section{Patients}

This study was conducted in the neonatal intensive care unit of Chang Gung Memorial Hospital Linkou Branch and was approved by the Institutional Review Board. As part of a hemodynamic monitoring project in the unit, echocardiographic findings and relevant hemodynamic information were collected prospectively into a database. We reviewed this database for very low birth weight (VLBW, $<1500$ g) preterm infants admitted between June 2015 to June 2016 who received ibuprofen treatment for PDA closure. We enrolled infants who had both echocardiography and EC data during the first treatment course. Infants with chromosomal anomaly or structural heart defect other than small patent foramen ovale or atrial septal defect were excluded. Demographic data, serial echocardiographic findings and respiratory support at time of ibuprofen administration were collected.

\section{Ibuprofen for PDA closure}

The decision to initiate ibuprofen for PDA closure was made based on individual's clinical condition (e.g. increased respiratory support or hypotension) and echocardiographic finding (e.g. large ductus $>2 \mathrm{~mm}$ or low peak systolic ductal flow). Per unit policy, infants with right-to-left or bidirectional shunting PDA, intraventricular hemorrhage grade $\geq 3$ or poor renal function (serum creatinine $>1.8 \mathrm{mg} / \mathrm{dl}$ or oligouria $<1 \mathrm{ml} / \mathrm{kg} / \mathrm{hr}$ ) were not candidates for ibuprofen treatment. The decision to treat with oral (ibuprofen oral suspension, [Center Laboratories Inc., Taipei, Taiwan]) or intravenous ibuprofen (Ibusine: Ibuprofen Lysine, [China Chemical \& Pharmaceutical Co., Taipei, Taiwan]) was also made by the attending neonatologist. One course of treatment for both oral and intravenous ibuprofen consisted of three consecutive doses of $10,5,5 \mathrm{mg} / \mathrm{kg} /$ dose given $24 \mathrm{~h}$ apart. Responder to ibuprofen treatment was defined as absence of ductal flow in echocardiography within $24 \mathrm{~h}$ after completion of treatment.

\section{Echocardiography}

Transthoracic echocardiography was performed using Sonos 7500 (Philips, Andover, Massachusetts, USA) with a $12 \mathrm{MHz}$ transducers. Serial echocardiography was performed in relation to ibuprofen administration: within an hour prior to dose \#1 ibuprofen (baseline), 18-24 h after dose \#1 and \#2 (during treatment), and 24 h after dose \#3 of ibuprofen (treatment completion). This timeframe was chosen to allow maximum effect of each dose. Echocardiographic parameters of the PDA were assessed, which includes ductal size and shunt direction by color Doppler mapping, maximum flow velocity by pulsed-wave Doppler, and left atrium to aortic root ratio (LA/Ao) and left ventricular fractional shortening (FS) by M-mode.

\section{Electrical Cardiometry (EC)}

EC (Aesculon, Osypka Medical, Berlin, Germany) was applied by attaching four standard surface electrocardiogram electrodes over the forehead, left lower neck, left mid-axillary line at the level of xiphoid process and lateral aspect of left thigh. EC was placed at least $1 \mathrm{~h}$ prior to dose \#1 ibuprofen and kept in situ until $24 \mathrm{~h}$ after completing treatment. Hemodynamic parameters by $\mathrm{EC}$, including $\mathrm{CO}_{\mathrm{EC}}$, heart rate $\left(\mathrm{HR}_{\mathrm{EC}}\right)$ and stroke volume $\left(\mathrm{SV}_{\mathrm{EC}}\right)$ were captured every 10 min during the study period and subsequently exported into a database using software Waveform Explorer by Osypka Medical. The original data that $1 \mathrm{~h}$ before treatment and 18$24 \mathrm{~h}$ after each ibuprofen dose were further averaged and analyzed (e.g. the baseline and 18-24 h following dose \#1, \#2 
and $\# 3$, respectively). Value of $\mathrm{CO}_{\mathrm{EC}}$ and $S \mathrm{~V}_{\mathrm{EC}}$ were weightadjusted as $\mathrm{ml} / \mathrm{kg} / \mathrm{min}$ and $\mathrm{ml} / \mathrm{kg}$.

\section{Matching}

In order to minimize confounders related to GA, weight and post-natal age, we matched each responder to a nonresponder with comparable GA \pm 1 week, weight $\pm 10 \% \mathrm{~g}$ and post-natal age \pm 7 days from the hemodynamic database. Furthermore, for comparison of $\mathrm{CO}_{\mathrm{EC}}$ between infants with and without PDA, we also matched above responders and non-responders respectively to our previously published reference [21] using the same criteria.

\section{Statistics}

Statistical analysis was performed using IBM SPSS Statistics version 20 (Armonk, NY, USA). Continuous variables in background demographics were tested using Mann-Whitney U test, while hemodynamic parameters by $\mathrm{EC}$ were tested with independent $t$-test between responders and non-responders or paired $t$-test was between two timing points. Repeated measures analysis of variance (RM-ANOVA) was applied to compare trends of hemodynamic parameters through the course. Categorical data were analyzed with Chi-square test or
Fisher's exact test. Analysis of the relationship between $\mathrm{CO}_{\mathrm{EC}}$ and ductal diameter or LA/Ao was by Pearson correlation coefficient. One-way ANOVA with Bonferroni correction was used to compare $\mathrm{CO}_{\mathrm{EC}}$ among responders, non-responders and the reference. Statistical significance was defined as two-sided $p<0.05$.

\section{Results}

During the study period, 303 VLBW preterm infants were admitted to our unit, of which 46 received ibuprofen treatment. There was complete data collection for both echocardiography and EC in 36 infants, and 11 of them were responders. After screening and matching, 9 out of 11 responders could be matched to 9 non-responders, and a total of 18 preterm infants were included. Their median (interquartile range) GA, weight and post-natal age at initiation of ibuprofen were 27.5 (26.6-28.6) weeks, 1038 (854-1218) g and 3.5 (3.0-4.0) days old, respectively. There was no significant difference in demographics, echocardiographic measurements, post-natal age, route of ibuprofen or respiratory support between responders and non-responders (Table 1). None received vasopressor or inotrope during the treatment course. Among 9 responders, 5 infants were found to have absence of ductal flow after dose \#1 ibuprofen, 2 infants after dose \#2,

Table 1 Clinical characteristics for responders and non-responders for ibuprofen treatment for PDA

\begin{tabular}{|c|c|c|c|}
\hline Demographics & $\begin{array}{l}\text { Responders } \\
(n=9)\end{array}$ & $\begin{array}{l}\text { Non-Responders } \\
(n=9)\end{array}$ & $\begin{array}{l}p \\
\text { value }^{a}\end{array}$ \\
\hline Gestational age (weeks) & $27.7(27.1-29.9)$ & $27.4(26.1-27.9)$ & 0.161 \\
\hline Weight (g) & 1135 (913-1318) & 1015 (830-1083) & 0.222 \\
\hline Apgar at $1 \mathrm{~min}$ & $7(5-8)$ & $6(3-7)$ & 0.077 \\
\hline Apgar at $5 \mathrm{~min}$ & $9(7-9)$ & $9(8-9)$ & 0.931 \\
\hline Male & $6(67 \%)$ & $2(22 \%)$ & 0.153 \\
\hline Cesarean section & $6(67 \%)$ & $7(78 \%)$ & 1.000 \\
\hline Small for gestational age & $2(22 \%)$ & $1(11 \%)$ & 1.000 \\
\hline \multicolumn{4}{|c|}{ Echocardiography prior to ibuprofen treatment } \\
\hline PDA diameter (mm) & $2.05(1.78-2.46)$ & $2.20(1.70-3.23)$ & 0.666 \\
\hline PDA diameter to weight $(\mathrm{mm} / \mathrm{kg})$ & $2.04(1.40-2.54)$ & $2.26(1.56-3.57)$ & 0.340 \\
\hline PDA maximum flow velocity (m/s) & $2.21(1.59-2.60)$ & $1.82(1.30-2.52)$ & 0.613 \\
\hline LA/Ao ratio & $1.47(1.27-1.76)$ & $1.50(1.44-1.87)$ & 0.370 \\
\hline Fractional shortening (\%) & $41.0(36.0-44.5)$ & $39.0(34.2-43.8)$ & 0.661 \\
\hline \multicolumn{4}{|l|}{ Condition prior to ibuprofen treatment } \\
\hline Post-natal age at dose \#1 (day) & $3.0(3.0-4.0)$ & $4.0(3.0-6.5)$ & 0.222 \\
\hline Oral ibuprofen & $8(89 \%)$ & $7(78 \%)$ & 1.000 \\
\hline Respiratory support & & & 0.183 \\
\hline Non-invasive ventilation & $5(56 \%)$ & $2(22 \%)$ & \\
\hline Conventional ventilation & $4(44 \%)$ & $5(56 \%)$ & \\
\hline High frequency ventilation & $0(0 \%)$ & $2(22 \%)$ & \\
\hline
\end{tabular}

PDA patent ductus arteriosus, $L A /$ Ao left atrium to aortic root diameter

Data are median (interquartile range) or $\mathrm{n}(\%)$

${ }^{\mathrm{a}} \mathrm{A} p$ value was tested by Mann-Whitney $\mathrm{U}$ test for continuous variables and Chi-square test or Fisher's exact test for categorical data 

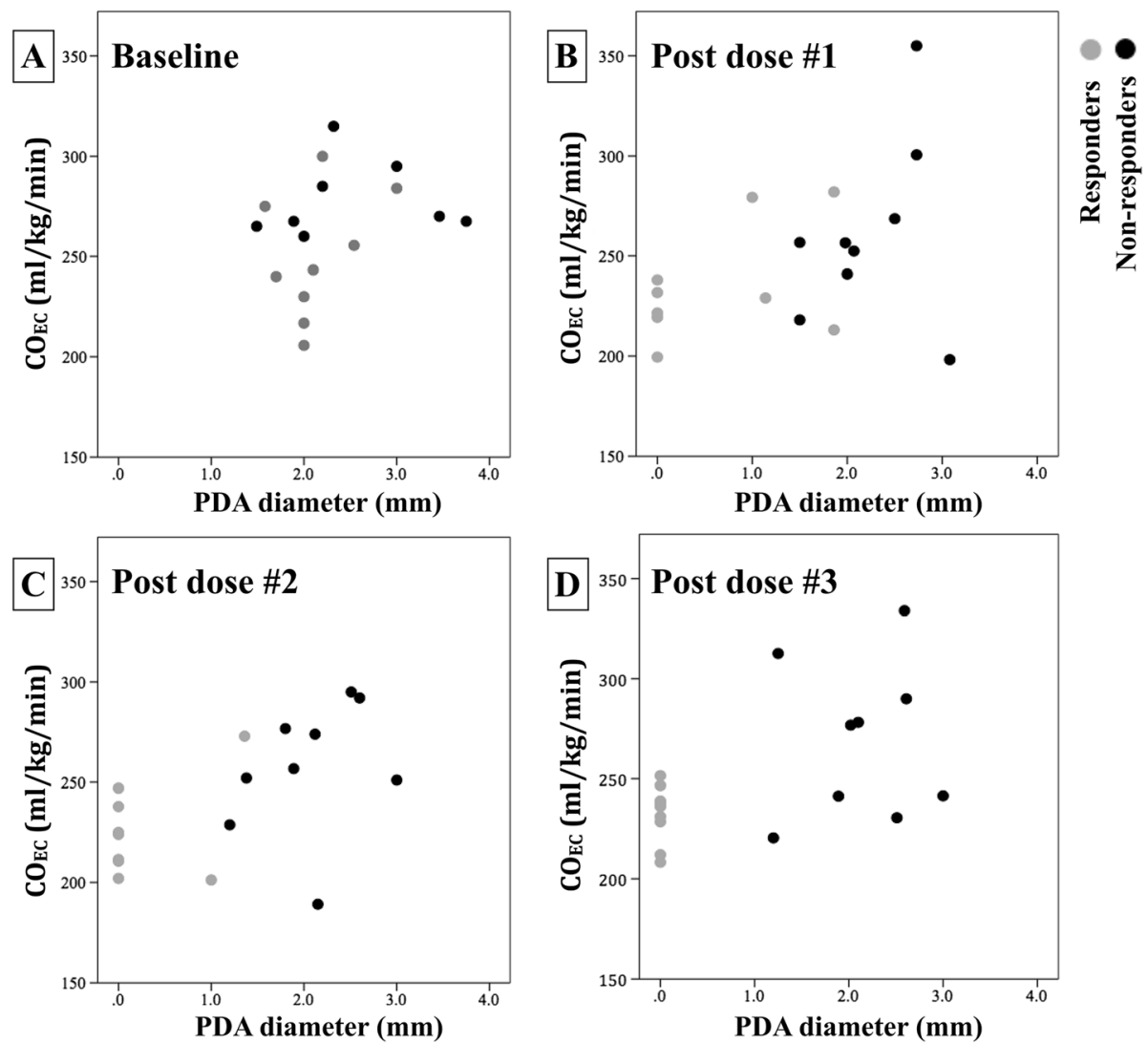

Fig. 1 Scatter diagrams of $\mathrm{CO}_{E C}$ and ductal diameter for preterm infants who responded (gray circles) and non-responded (black circles) to ibuprofen treatment for PDA. Four timing points were plotted: $1 \mathrm{~h}$ prior to treatment (baseline, a) and 18-24 h post each dosage of ibuprofen (b, c and $\mathbf{d}$, respectively). $\mathrm{CO}_{\mathrm{EC}}$, cardiac output by electrical cardiometry; PDA, patent ductus arteriosus

and 2 infants after dose \#3 (Fig. 1 a-d). Furthermore, there was positive correlations between $\mathrm{CO}_{\mathrm{EC}}$ and ductal diameter $(r=0.521, p<0.001)$ and LA/Ao $(r=0.374, p<0.001)$.

Non-responders had higher $\mathrm{CO}_{\mathrm{EC}}$ compared to responders throughout the treatment course (RM-ANOVA between-subject $p=0.005$ ). This discrepancy was most significant prior to ibuprofen treatment $(282 \pm 21$ vs. $250 \pm 31 \mathrm{ml} / \mathrm{kg} / \mathrm{min}, \quad p=0.022$ ), at $24 \mathrm{~h}$ post dose \#2 (257 \pm 33 vs. $226 \pm 23 \mathrm{ml} / \mathrm{kg} / \mathrm{min}, p=0.034)$, and $24 \mathrm{~h}$ post dose \#3 (270 \pm 39 vs. $232 \pm 14 \mathrm{ml} / \mathrm{kg} / \mathrm{min}, \mathrm{p}=0.022)$ (Fig. 2a). No significant differences in $\mathrm{HR}_{\mathrm{EC}}$ or $\mathrm{SV}_{\mathrm{EC}}$ were found between the two groups (Fig. $2 \mathrm{~b}$ and c).

When analyzing within-subject changes throughout the treatment course, there were no significant changes of $C \mathrm{CO}_{\mathrm{EC}}, \mathrm{HR}_{\mathrm{EC}}$ or $\mathrm{SV}_{\mathrm{EC}}$ in either responders or nonresponders (RM-ANOVA). The average alteration of $\mathrm{CO}_{\mathrm{EC}}$ was $-7 \% \pm 12 \%$ for responders and $-6 \% \pm 16 \%$ for non-responders. On the other hand, when comparing baseline $\mathrm{CO}_{\mathrm{EC}}$ to the earliest time point when no ductal flow was visualized by echocardiography, there was a significant but small-scale reduction in $\mathrm{CO}_{\mathrm{EC}}$ by $25 \mathrm{ml} /$ $\mathrm{kg} / \mathrm{min}$ or $10 \%(250 \pm 31$ vs. $225 \pm 17 \mathrm{ml} / \mathrm{kg} / \mathrm{min}$, paired $t$-test $p=0.031)$ (Table 2). However, we found 4/9 (44\%) of non-responders had $>10 \%$ reduction of $\mathrm{CO}_{\mathrm{EC}}$ at some timing points as well.

Another 18 infants without PDA were matched for baseline $\mathrm{CO}_{\mathrm{EC}}$ comparison. Their median GA and weight were $28.6(28.0-30.2)$ weeks and 1175 (1005-1312) g, respectively, and were all 3-4 days old. No demographic difference existed among these three groups (responders, non-responders and the reference). There was a significant stepwise increment in baseline $\mathrm{CO}_{\mathrm{EC}}$ from infants with no PDA $(207 \pm 28 \mathrm{ml} / \mathrm{kg} / \mathrm{min})$, to infants with PDA, responders $(250 \pm 31 \mathrm{ml} / \mathrm{kg} / \mathrm{min})$, to infants with $\mathrm{PDA}$, non-responders $(282 \pm 21 \mathrm{ml} / \mathrm{kg} / \mathrm{min}, p<0.001)$ (Fig. 3).

\section{Discussions}

In this study, we showed the potential of EC to continuously monitor changes in $\mathrm{CO}_{\mathrm{EC}}$ among preterm infants. By carefully matching target infants, we demonstrated that infants with PDA had higher baseline $\mathrm{CO}_{\mathrm{EC}}$ and there was no significant $\mathrm{CO}_{\mathrm{EC}}$ alteration during ibuprofen treatment for ductal closure.

Our finding indicated that preterm infants with PDA have significantly higher baseline $\mathrm{CO}_{\mathrm{EC}}$ compared to agematched reference, and that baseline $\mathrm{CO}_{\mathrm{EC}}$ is positively 


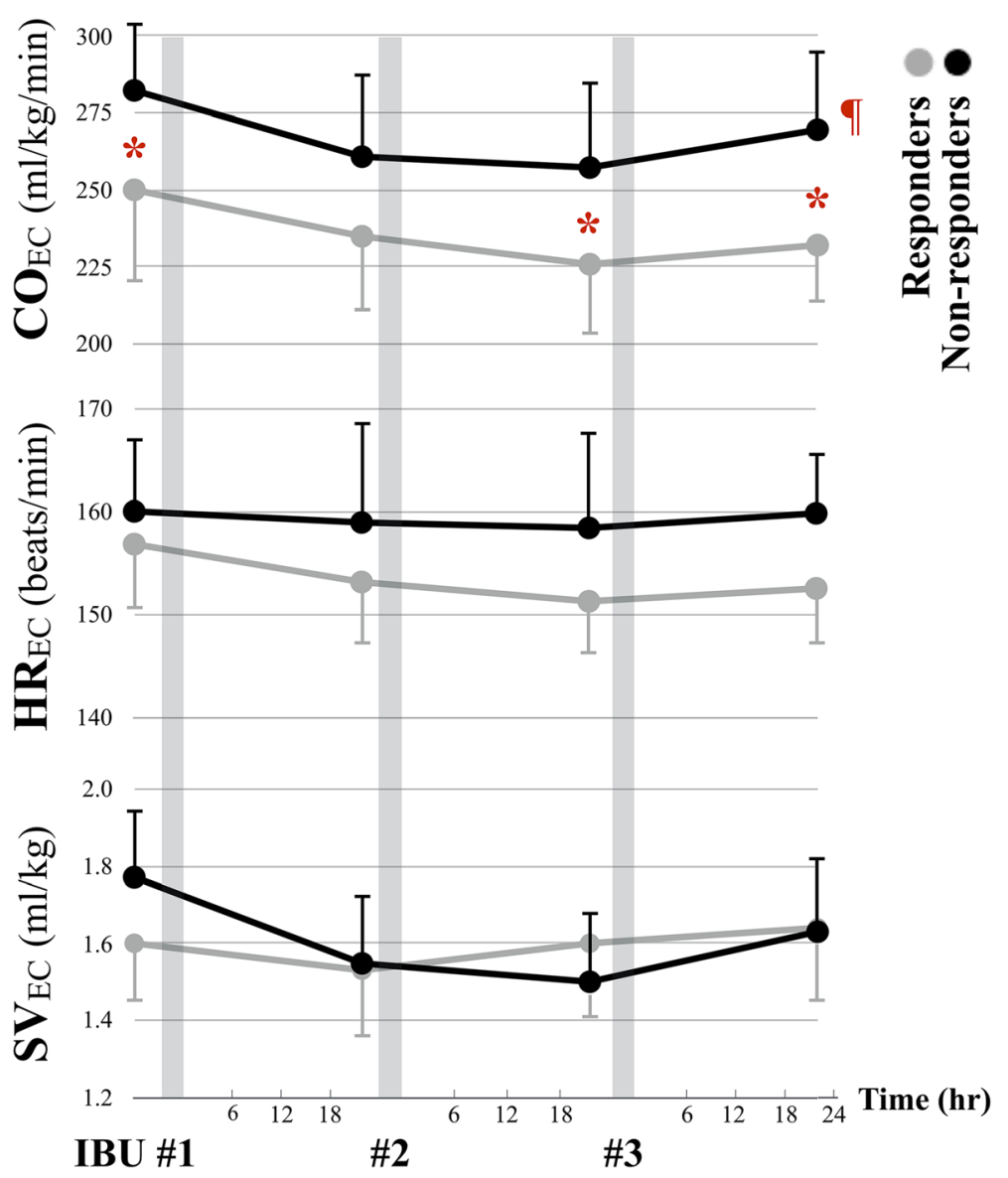

Fig. 2 Trends charts of $\mathrm{CO}_{E C}, H R_{E C}$ and $S V_{E C}$ for responders (gray line) and non-responders (black line) through ibuprofen treatment. Three gray bands indicate the time of each ibuprofen administration. Although there was no remarkable alteration of $\mathrm{CO}_{\mathrm{EC},} \mathrm{HR}_{\mathrm{EC}}$ and $S V_{E C}$ within each group, non-responders had significantly higher $\mathrm{CO}_{\mathrm{EC}}$ than responders through the course (between-subject $\left.p=0.005\right)$ ( $\left.\mathbf{(}\right)$, especially at the timing prior to dose \#1 ibuprofen, $18-24 \mathrm{~h}$ post dose \#2 and 18-24 h post dose \#3, respectively $\left(^{*}\right)$. COEC, cardiac output; HR $\mathrm{R}_{\mathrm{EC}}$, heart rate; SVEC, stroke volume; all measured by electrical cardiometry

Table 2 Hemodynamic changes at specific timing points

\begin{tabular}{|c|c|c|c|c|}
\hline & & Responders $(n=9)$ & Non-responders $(n=9)$ & $p$ value \\
\hline \multirow[t]{3}{*}{$\overline{C O_{E C}}(\mathrm{ml} / \mathrm{kg} / \mathrm{min})$} & Prior to dose \#1 & $250 \pm 31$ & $282 \pm 21$ & $0.022^{b}$ \\
\hline & No ductal flow ${ }^{a}$ & $225 \pm 17^{c}$ & N/A & N/A \\
\hline & 18-24 h after dose \#3 & $232 \pm 15$ & $270 \pm 39$ & $0.021^{b}$ \\
\hline \multirow[t]{3}{*}{$\mathrm{HR}_{\mathrm{EC}}$ (beats/min) } & Prior to dose \#1 & $157 \pm 7$ & $160 \pm 8$ & 0.394 \\
\hline & No ductal flow ${ }^{a}$ & $151 \pm 7$ & N/A & N/A \\
\hline & 18-24 h after dose \#3 & $153 \pm 8$ & $160 \pm 6$ & 0.077 \\
\hline \multirow[t]{3}{*}{$S V_{E C}(\mathrm{ml} / \mathrm{kg})$} & Prior to dose \#1 & $1.59 \pm 0.23$ & $1.77 \pm 0.30$ & 0.165 \\
\hline & No ductal flow ${ }^{a}$ & $1.50 \pm 0.15$ & N/A & N/A \\
\hline & 18-24 h after dose \#3 & $1.63 \pm 0.29$ & $1.63 \pm 0.25$ & 0.926 \\
\hline
\end{tabular}

CO cardiac output, $H R$ heart rate, SV stroke volume, EC electrical cardiometry, N/A not applicable

Data are mean $( \pm \mathrm{SD})$

${ }^{\text {a}}$ Five infants' ductal flow disappeared in color Doppler post dose \#1, two post dose \#2 and two post dose \#3

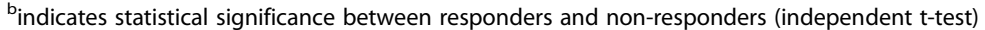

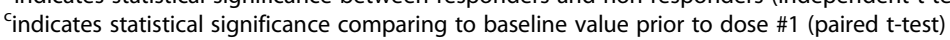




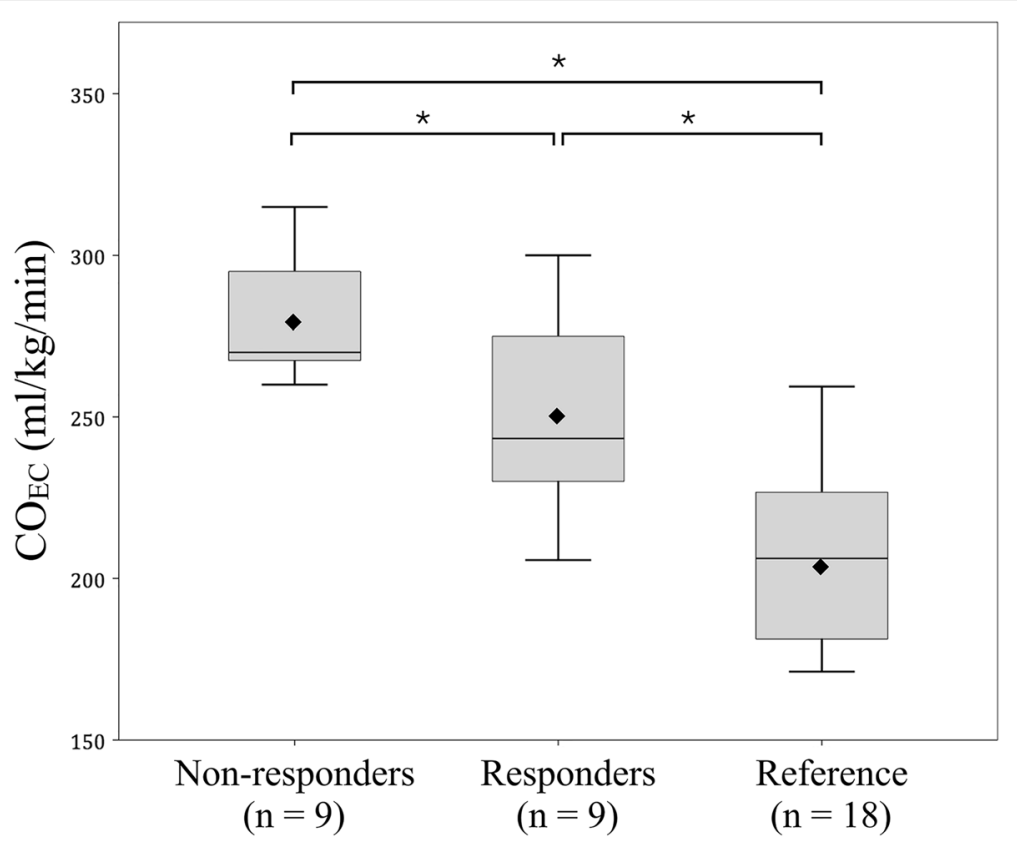

Fig. 3 Box plot of baseline $\mathrm{CO}_{\mathrm{EC}}$ for responders, non-responders and matched reference. The horizontal lines are median $\mathrm{CO}_{\mathrm{EC}}$ and the diamond marks are mean of $\mathrm{CO}_{\mathrm{EC}}$ for respective group. Mean $\mathrm{CO}_{\mathrm{EC}}$ of three groups were statistically different, especially non-responders had the highest $\mathrm{CO}_{\mathrm{EC}} \cdot \mathrm{CO}_{\mathrm{EC}}$, cardiac output by electrical cardiometry

correlated to PDA diameter and LA/Ao. The positive correlation suggests that infants with greater $\mathrm{CO}_{\mathrm{EC}}$ have a higher likelihood of more significant ductal shunting. It was interesting to find that only the baseline $\mathrm{CO}_{\mathrm{EC}}$, but not ductal diameter, maximum ductal flow or LA/Ao, was significantly different between responders and nonresponders in our study. It can be reasoned that with high left-to-right ductal shunting, $\mathrm{CO}$ represents the sum of systemic flow plus ductal shunting, and hence increases in $\mathrm{CO}$ is a compensation and proportional to ductal shunting $[7,13]$. Furthermore, only $\mathrm{CO}_{\mathrm{EC}}$ but not $\mathrm{HR}_{\mathrm{EC}}$ or $\mathrm{SV}_{\mathrm{EC}}$ was significantly different between responders and nonresponders. This may indicate that $\mathrm{CO}$ represents the sum of left ventricular work, i.e., HR and SV, to compensate for the ductal steal effect. It also suggests that $\mathrm{CO}$ may be a more comprehensive surrogate in determining the degree of ductal shunting. The difference in baseline $\mathrm{CO}_{\mathrm{EC}}$ between responders and non-responders is compatible with previous studies that infants with larger ductal shunting may response poorly to COX inhibitor $[4,8]$.

We observed no significant $\mathrm{CO}_{\mathrm{EC}}$ alteration through ibuprofen treatment for PDA closure. Although there was a mean decrease of $\mathrm{CO}_{\mathrm{EC}}$ by $10 \%$ on initial ductal closure, this reduction of $\mathrm{CO}_{\mathrm{EC}}$ cannot be an indicator for ductal closure because non-responders may also had $>10 \%$ reduction of $\mathrm{CO}_{\mathrm{EC}}$ through the course. Moreover, the small-scale decline is unlike our previous study that a $26 \%$ decrease in $\mathrm{CO}_{\mathrm{EC}}$ at time of ductal ligation [22]. We speculate that the effect of ibuprofen in inducing ductal closure was progressive or intermittent while allowing time for the myocardium to adapt to the hemodynamic changes. This is further supported by the fact that no infant in our study required inotropic support, which is needed in infants with post-ligation hemodynamic instability.

There is a similar study utilizing EC to monitor CO during attempted pharmacological closure of PDA by intravenous ibuprofen in preterm infants [23], of which, a fall in median $\mathrm{CO}_{\mathrm{EC}}$ from 290 to $240 \mathrm{ml} / \mathrm{kg} / \mathrm{min}$ (17\%) $72 \mathrm{~h}$ after the initiation of treatment was found. However, the study is limited by its small case number ( 6 responders) and a wide overlap of $\mathrm{CO}_{\mathrm{EC}}$ between baseline and $72 \mathrm{~h}$ after the first dose ibuprofen. In addition, 2 out of 6 infants in this study received dopamine infusion before ibuprofen treatment and dopamine was tapered off at the end of ibuprofen treatment, which can confound the baseline and post-treatment $\mathrm{CO}_{\mathrm{EC}}$ measurements [24]. The dopamine infusion may have contributed to the larger discrepancy between baseline and posttreatment $\mathrm{CO}_{\mathrm{EC}}$ in this study.

Some limitations should be addressed. Firstly, the sample size of current study was small. The number of responders limited the power to demonstrate exact $\mathrm{CO}_{\mathrm{EC}}$ changes and to detect a confident cut-off $\mathrm{CO}_{\mathrm{EC}}$ to assess treatment response. Secondly, using echocardiography to detect the exact timing of ductal closure during ibuprofen treatment is clinically complex. We are only able to use the earliest available echocardiography data that indicates no ductal flow to assess $\mathrm{CO}_{\mathrm{EC}}$ alteration. This also limited the ability to estimate short-term alteration 
following ductal closure. We also lacked other echocardiographic markers for PDA severity such as superior vena cava flow for systemic blood flow [25] or left pulmonary artery end-diastolic flow for pulmonary overcirculation [26]. Thirdly, some demographic information was not included into analysis. Closure of PDA is a multifactorial interaction, complete respiratory evaluation inclusive of arterial blood gas analysis, inhaled oxygen fraction and mean airway pressure, and even genetic disposition or pharmacokinetic difference should be considered. Lastly, we merely analyzed infants who received the first treatment course. Since it is known that the ibuprofen response is accumulative, it is warranted to enroll those receiving repeated courses in a future study.

\section{Conclusions}

The decrease in $\mathrm{CO}_{\mathrm{EC}}$ during pharmacological closure of PDA is less drastic. Baseline CO measured by EC is higher in infants with PDA compared to those without PDA, especially non-responders had higher $\mathrm{CO}_{\mathrm{EC}}$ at baseline compared to responders. Monitoring $\mathrm{CO}_{\mathrm{EC}}$ is clinically applicable in bedside hemodynamic trending; however, a detailed assessment of hemodynamic compensation to a significant ductal shunt and to estimate pharmacological closure of the duct requires further studies.

\section{Abbreviations \\ CO: Cardiac output; COX: Cyclooxygenase; EC: Electrical cardiometry; HR: Heart rate; PDA: Patent ductus arteriosus; RM-ANOVA: Repeated measures analysis of variance; SV: Stroke volume; VLBW: Very low birth weight}

\section{Acknowledgments \\ Not applicable.}

\section{Authors' contributions}

$\mathrm{KH}$ has contributed to the design of the study, measurements, statistical analysis, has drafted the initial and the revised version of the manuscript. TW has contributed to the statistical analysis, writing of the manuscript and critically reviewed the manuscript. IW, ML, SH, HH, TM and $\mathrm{CL}$ participated in the design of the study and measurements, coordination and helped to draft the manuscript. RL participated in the design of the study and critically reviewed the manuscript. All authors read and approved the final manuscript.

\section{Funding}

This study was supported by the Ministry of Health and Welfare of Taiwan aiming to improve quality of pediatric critical care. The funding body had no role in designing the study, collection, analysis, and interpretation of data, or in writing the manuscript.

\section{Availability of data and materials}

The dataset supporting the conclusions of this article is available by inquiring to khsu@cgmh.org.tw.

\section{Ethics approval and consent to participate}

This study was approved by the Institutional Review Board (IRB) of Chang Gung Memorial Hospital Linkou Branch (project number: 104 - 9357A).

\section{Consent for publication}

Not applicable.

\section{Competing interests}

The authors declare that they have no competing interests.

\section{Author details}

'Division of Neonatology, Department of Pediatrics, Chang Gung Memorial Hospital Linkou Branch, Taoyuan, Taiwan. ${ }^{2}$ Graduate Institute of Clinical Medical Science, Chang Gung University, Taoyuan, Taiwan. ${ }^{3}$ Center for Fetal and Neonatal Medicine, Division of Neonatology, Children's Hospital Los Angeles and Keck School of Medicine, University of Southern California, Los Angeles, CA, USA. ${ }^{4}$ Division of Neonatology, Department of Pediatrics, Chang Gung Memorial Hospital Keelung Branch, Keelung, Taiwan.

Received: 16 February 2019 Accepted: 28 May 2019

Published online: 05 June 2019

References

1. Noori S, Michael M, Friedlich P, Bright B, Gottipati V, Seri I, et al. Failure of ductus arteriosus closure is associated with increased mortality in preterm infants. Pediatrics. 2009;123(1):e138-44.

2. Neumann R, Sm S, Buhrer C. Oral ibuprofen versus intravenous ibuprofen or intravenous indomethacin for the treatment of patent ductus arteriosus in preterm infants: a systematic review and meta-analysis. Neonatology. 2012;102(1):9-15.

3. Koch J, Gaynelle H, Roy L, Brown S, Ramaciotti C, Rosenfeld CR. Prevalence of spontaneous closure of the ductus arteriosus in neonates at a birth weight of 1000 grams or less. Pediatrics. 2006;117(4):1113-21.

4. Van Overmeire B, Smets K, Lecoutere D, Van de Broek H, Weyler J, De Groote $\mathrm{K}$, et al. A comparison of ibuprofen and indomethacin for closure of patent ductus arteriosus. N Engl J Med. 2000;343(10):674-81.

5. Chorne N, Jegatheesan P, Lin E, Shi R, Clyman Rl. Risk factors for persistent ductus arteriosus patency during indomethacin treatment. J Pediatr. 2007;151(6):629-34.

6. Heuchan AM, Clyman RI. Managing the patent ductus arteriosus: current treatment options. Arch Dis Child Fetal Neonatal Ed. 2014;99(5):F431-6.

7. El Hajjar M, Vaksmann G, Rakza T, Kongolo G, Storme L. Severity of the ductal shunt: a comparison of different markers. Arch Dis Child Fetal Neonatal Ed. 2005:90(5):F419-22

8. Desandes R, Jellimann JM, Rouabah M, Haddad F, Desandes E, Boubred F, et al. Echocardiography as a guide for patent ductus arteriosus ibuprofen treatment and efficacy prediction. Pediactr Crit Care Med. 2012;13(3):324-7.

9. Sehgal A, McNamara PJ. Does echocardiography facilitate determination of hemodynamic significance attributable to the ductus arteriosus? Eur J Pediatr. 2009;168(8):907-14.

10. Walther FJ, Kim D, Ebrahimi M, Siassi B. Pulsed Doppler measurement of left ventricular output as early predictor of symptomatic patent ductus arteriosus in very preterm infants. Biol Neonate. 1989:56(3):121-8.

11. Hirsimäki H, Kero P, Wanne O, Erkkola R, Makoi Z. Doppler-derived cardiac output in healthy newborn infants in relation to physiological patency of the ductus arteriosus. Pediatr Cardiol. 1988;9(2):79-83.

12. Shimada S, Kasai T, Konishi M, Fujiwara T. Effects of patent ductus arteriosus on left ventricular output and organ blood flows in preterm infants with respiratory distress syndrome treated with surfactant. J Pediatr. 1994;125(2):270-7.

13. Lindner W, Seidel M, Versmold HT, Dohlemann C, Riegel KP. Stroke volume and left ventricular output in preterm infants with patent ductus arteriosus. Pedaitr Res. 1990;27(3):278-81.

14. El-Khuffash A, Jain A, McNamara P. Ligation of the patent ductus arteriosus in preterm infants: understanding the physiology. J Pediatr. 2013;162(6):1100-6.

15. Mertens L, Seri I, Marek J, Arlettaz R, Barker P, McNamara P, et al. Targeted neonatal echocardiography in the neonatal intensive care unit: practice guidelines and recommendations for training. Writing group of the American Society of Echocardiography (ASE) in collaboration with the European Association of Echocardiography (EAE) and the Association for European Pediatric Cardiologists (AEPC). J Am Soc Echocardiogr. 2011; 24(10):1057-78.

16. de Boode WP. Cardiac output monitoring in newborns. Early Hum Dev. 2010;86(3):143-8.

17. Noori S, Drabu B, Soleymani S, Seri I. Continuous non-invasive cardiac output measurements in the neonate by electrical velocimetry: a comparison with echocardiography. Arch Dis Child Fetal Neonatal Ed. 2012; 97(5):F340-3.

18. Song R, Rich W, Kim JH, Finer NN, Katheria AC. The use of electrical cardiometry for continuous cardiac output monitoring in preterm neonates: a validation study. Am J Perinatol. 2014;31(12):1105-10. 
19. Grollmuss O, Gonzalez P. Non-invasive cardiac output measurement in low and very low birth weight infants: a method comparison. Front Pediatr. 2014;2:16.

20. Hsu KH, Wu TW, Wu IH, Lai MY, Hsu SY, Huang HW, et al. Electrical cardiometry to monitor cardiac output in preterm infants with patent ductus arteriosus: a comparison with echocardiography. Neonatology. 2017;112(3):231-7.

21. Hsu KH, Wu TW, Wang YC, Lim WH, Lee CC, Lien R. Hemodynamic reference for neonates of different age and weight: a pilot study with electrical cardiometry. J Perinatol. 2016;36(6):481-5.

22. Lien R, Hsu KH, Chu JJ, Chang YS. Hemodynamic alterations recorded by electrical cardiometry during ligation of ductus arteriosus in preterm infants. Eur J Pediatr. 2015;174(4):543-50.

23. Rodriguez Sanchez de la Blanca A, Sanchez Luna M, Gonzalez Pacheco N, Arriaga Redondo M, Navarro Patino N. Electrical velocimetry for noninvasive monitoring of the closure of the ductus arteriosus in preterm infants. Eur J Pediatr. 2018:177(2):229-35.

24. Padbury JF, Agata Y, Baylen BG, Ludlow JK, Polk DH, Goldblatt E, et al. Dopamine pharmacokinetics in critically ill newborn infants. J Pediatr. 1987;1 10(2):293-8.

25. Kluckow M, Evans N. Superior vena cava flow in newborn infants: a novel marker of systemic blood flow. Arch Dis Child Fetal Neonatal Ed. 2000;82(3):F182-7.

26. Suzmura H, Nitta A, Tanaka O. Diastolic flow velocity of left pulmonary artery of patent ductus arteriosus in preterm infants. Pediatr Int. 2001;43:146-51.

\section{Publisher's Note}

Springer Nature remains neutral with regard to jurisdictional claims in published maps and institutional affiliations.

Ready to submit your research? Choose BMC and benefit from:

- fast, convenient online submission

- thorough peer review by experienced researchers in your field

- rapid publication on acceptance

- support for research data, including large and complex data types

- gold Open Access which fosters wider collaboration and increased citations

- maximum visibility for your research: over $100 \mathrm{M}$ website views per year

At $\mathrm{BMC}$, research is always in progress.

Learn more biomedcentral.com/submissions 